\title{
Modified Transdermal Technologies: Breaking the Barriers of Drug Permeation via the Skin
}

\author{
Ritesh Kumar and Anil Philip* \\ Department of Pharmaceutics, Rajiv Academy for Pharmacy, Mathura-286001, Uttar Pradesh, India.
}

\begin{abstract}
Transdermal drug technology specialists are continuing to search for new methods that can effectively and painlessly deliver larger molecules in therapeutic quantities to overcome the difficulties associated with the oral route, namely poor bioavailability due to hepatic metabolism (first pass) and the tendency to produce rapid blood level spikes (both high and low). Transdermal delivery can improve the therapeutic efficacy and safety of drugs by more precise (i.e., site-specific) way but spatial and temporal placement within the body is required to reduce both the size and number of doses necessary to achieve the objective of systemic medication through topical application to the intact skin surface. Modulation of formulation excipients and addition of chemical enhancers can increase drug flux but that is not sufficient to ensure delivery of pharmacologically effective concentration of drug therefore, several new active rate controlled TDDS technologies (electrically-based, structure-based, velocity-based, etc.) have been developed and commercialized for the transdermal delivery of 'troublesome' drugs. This review article covers most of the new active transport technologies involved in enhancing the transdermal permeation into an effective DDS. In-depth analysis, formulation approaches, applications, advantages and disadvantages of these newer technologies are discussed.
\end{abstract}

Keywords: Transdermal drug delivery, microneedles, macroflux, iontophoresis, ultrasound, powderject, skin abrasion.

*Correspondence: 091-0565-2425159, Fax: 091-0565-2425159 E-mail: anilphilip@sancharnet.com, philipanil23@yahoo.co.in 


\section{INTRODUCTION}

Nowadays, the transdermal route has become one of the most successful and innovative focus for research in drug delivery, with around $40 \%$ of the drug candidate being under clinical evaluation related to transdermal or dermal systems. The technology has a proven record of FDA approval since the first transdermal patch was approved in 1981. The market for transdermal products has been in a significant upward trend and this is likely to continue for the foreseeable future. An increasing number of TDD products continue to deliver real therapeutic benefit to patients around the world. More than 35 TDD products have now been approved for sale in the US, and approximately 16 active ingredients have been approved for use globally. Statistics reveal a market of $\$ 12.7$ billion in the year 2005 that is expected to increase to $\$ 21.5$ billion in the year 2010 and \$ 31.5 billion in the year 2015 . $^{1}$ For transdermal drug delivery system to be effective, the drug must obviously be able to penetrate the skin barrier and reach to target site. ${ }^{2}$ Table 1 gives information on different drugs administered as conventional transdermal patches.

\section{Advantages of Transdermal Drug Delivery System (TDDS)}

The advantages of transdermal delivery over other delivery modalities are as follows:

- Avoidance of 'first-pass' metabolism of drugs.

- Peak plasma levels of drugs are reduced, leading to decreased side effects.

- Reduction of fluctuations in plasma levels of drugs.

- Utilization of drug candidates with short half-life and low therapeutic index ${ }^{4}$

- Easy termination of drug delivery in case of toxicity.

- Reduction of dosing frequency and enhancement of patient compliance. ${ }^{5}$

For transdermal drug delivery system to be effective, the drug must obviously be able to penetrate the skin barrier and reach the target site. $^{6}$
Limitations for a drug candidate to be incorporated into a transdermal delivery system are: -

- Higher molecular weight candidates $(>500 \mathrm{Da})$ fail to penetrate the stratum corneum.

- Drugs with very low or high partition coefficient fail to reach systemic circulation.

- High melting drugs, due to their low solubility both in water and fat. ${ }^{7}$

Such candidates cannot be delivered across the skin without effectively making suitable modifications in the conventional transdermal delivery systems.

The skin is one of the most extensive and readily accessible organs of the human body. It receives about one-third of the blood circulation through the body. It serves as a barrier against physical and chemical attacks and shields the body from invasion by microorganisms. The skin barrier properties reside in outermost layer, the stratum corneum. The stratum corneum is effectively a $10-15 \mu \mathrm{m}$ thick matrix of dehydrated, dead keratinocytes (coenocytes) embedded in a lipid matrix. There are two important layers in the skin: the dermis and epidermis. The outer most layer, the epidermis, is approximately 100 to 150 $\mu \mathrm{m}$ thick, has no blood flow and includes a layer within it known as the stratum corneum. Beneath the epidermis, the dermis contains the system of capillaries that transport blood throughout the body. If the drug is able to penetrate the stratum corneum, then it can enter the blood stream and the process is known as passive diffusion.

There are two concepts in the design of transdermal delivery, namely, the reservoir type and the matrix type. Others are actually extensions of these two concepts and both involve diffusion of drug molecule through the skin barrier ${ }^{8}$.

Modulation of formulation excipients and addition of chemical enhancers, such as fatty acids, surfactants, esters and alcohols that exert their action via a temporary alteration of barrier properties of the stratum corneum by various mechanisms, including enhancing 
Table 1: Transdermal patches available in the market $^{3}$

\begin{tabular}{|c|c|c|c|}
\hline Brand Name & Drug & Manufacturer & Indication \\
\hline Alora & Estradiol & TheraTech/Proctol and Gamble & $\begin{array}{l}\text { Postmenstrual } \\
\text { syndrome }\end{array}$ \\
\hline Androderm & Testosterone & TheraTech/GlaxoSmithKline & $\begin{array}{l}\text { Hypogonadism in } \\
\text { males }\end{array}$ \\
\hline Catapres TTS $^{\circledR}$ & Clonidine & Alza/Boehinger Ingelheim & Hypertension \\
\hline Climaderm & Estradiol & Ethical Holdings/Wyeth-Ayerest & $\begin{array}{l}\text { Postmenstrual } \\
\text { syndrome }\end{array}$ \\
\hline Climara & Estradiol & $\begin{array}{l}\text { 3M Pharmaceuticals/Berlex } \\
\text { Labs }\end{array}$ & $\begin{array}{l}\text { Postmenstrual } \\
\text { syndrome }\end{array}$ \\
\hline Deponit & Nitroglycerin & Schwarz-Pharma & Angina pectoris \\
\hline Duragesic $^{\circledR}$ & Fentanyl & Alza/Janssen Pharmaceutica & $\begin{array}{l}\text { Moderate/severe } \\
\text { pain }\end{array}$ \\
\hline Estraderm & Estradiol & Alza/Norvatis & $\begin{array}{l}\text { Postmenstrual } \\
\text { syndrome }\end{array}$ \\
\hline Fematrix & Estrogen & $\begin{array}{l}\text { Ethical Holdings/Solvay } \\
\text { Healthcare Ltd. }\end{array}$ & $\begin{array}{l}\text { Postmenstrual } \\
\text { syndrome }\end{array}$ \\
\hline FemPatch & Estradiol & Parke-Davis & $\begin{array}{l}\text { Postmenstrual } \\
\text { syndrome }\end{array}$ \\
\hline Habitraol & Nicotine & Novartis & Smoking cessation \\
\hline Minitran & Nitroglycerin & 3M Pharmaceuticals & Angina pectoris \\
\hline Nicoderm $^{\circledR}$ & Nicotine & Alza/GlaxoSmithKline & Smoking cessation \\
\hline Nitrodisc & Nitroglycerin & Roberts Pharmaceuticals & Angina pectoris \\
\hline Nitro-dur & Nitroglycerin & Key Pharmaceuticals & Angina pectoris \\
\hline Nuvelle TS & $\begin{array}{l}\text { Estrogen/Proge } \\
\text { sterone }\end{array}$ & Ethical Holdings/Schering & $\begin{array}{l}\text { Hormone } \\
\text { replacement therapy }\end{array}$ \\
\hline Prostep & Nicotine & Elan Corp./Lederle Labs & Smoking cessation \\
\hline Testoderm TTS ${ }^{\circledR}$ & Testosterone & Alza & $\begin{array}{l}\text { Hypogonadism in } \\
\text { males }\end{array}$ \\
\hline Transderm- Scop ${ }^{\circledR}$ & Scopolamine & Alza/Norvatis & Motion sickness \\
\hline Transderm- Nitro ${ }^{\circledR}$ & Nitroglycerin & Alza/Norvatis & Angina pectoris \\
\hline
\end{tabular}

Table 2: Comparative physiochemical and clinical properties for each TDDS technology

\begin{tabular}{lllll}
\hline Technology & Polarity & $\begin{array}{l}\text { Molecular } \\
\text { Weight }\end{array}$ & Melting Point $\left({ }^{\circ} \mathbf{C}\right)$ & $\begin{array}{l}\text { Daily Dose } \\
\text { (mg/day) }\end{array}$ \\
\hline TDS Patch & Neutral & $<500$ & $<150$ & $<10$ \\
lontophoresis & lonic & No limit & No limit & $<20$ \\
Sonophoresis & Neutral & No limit & No limit & $<20$ \\
Heat & Neutral & $<500$ & $<150$ & $<15$ \\
Macroflux & All & No limit & No limit & $<30$ \\
\hline
\end{tabular}

solubility, partitioning the stratum corneum, fluidizing the crystalline structure of the stratum corneum and causing dissolution of stratum corneum lipids can enhance drug flux. However, due to low permeability coefficients of macromolecules, the enhancement effects required to ensure delivery of pharmacologically effective concentrations are likely to be beyond the capability of chemical enhancers tolerated by the skin. Therefore, several new active transport technologies have been developed for the transdermal delivery of 'troublesome' drugs (Fig 1) as the development of modified novel physical techniques have overcome the limitations of chemical enhancement techniques. ${ }^{9,10}$ 


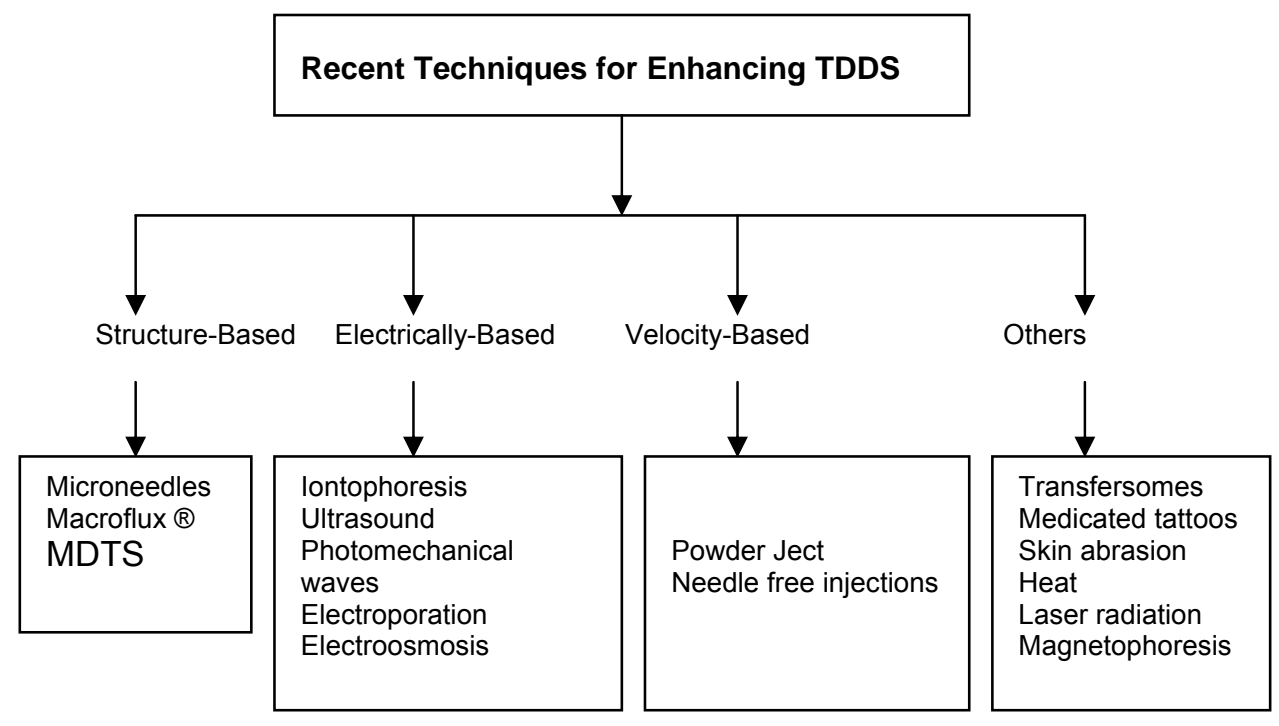

Fig 1: Recent techniques based on active transport for enhancing TDDS.

\section{Structure-Based Enhancement Techniques Microfabricated Microneedles}

Microfabricated microneedles are devices which are hybrids of the hypodermic needle and transdermal patch through the use of microscopic needles that can deliver the drug effectively (like a hypodermic needle). Their small size offers the potential advantages of delivering large molecules across the stratum corneum without extreme pain to the patients. ${ }^{11}$

The first microneedles systems consisted of a drug reservoir and a plurality of projections (microneedles) extending from the reservoir, which penetrate the stratum corneum and epidermis to deliver the $\operatorname{drug}^{12,}{ }^{13}$. The microneedle concept employs an array of micron-scale needles that can deliver drug into the epidermis and dermis, which ultimately leads to uptake by the capillaries for systemic delivery but not so far that microneedles hit the nerves. This is the reason for the device being less painful to patients. The most common material used for microfabrication of needles is silicon. These microneedles have extremely sharp tips (radius of curvature, $<1 \mu \mathrm{m}$ ) that facilitate easy piercing of the skin. Individual silicon needles measuring approximately $150 \mu \mathrm{m}$ in length and with $80 \mu \mathrm{m}$ base diameter are fabricated onto arrays of approximately 400 microneedles (approx. $3 \times 3 \mathrm{~mm}$ ). Needles with hollow centers have also been produced, each containing a bore of 5-70 $\mu \mathrm{m}$ (depending on the required design) through which drug can be administered. $A$ broad range of compounds such as calcein $(623 \mathrm{Da})$, insulin $(6000 \mathrm{Da}), \mathrm{BSA}(66000 \mathrm{Da})$ and polymeric nanoparticles are delivered at significant rates through skin permeabilized by microfabricated microneedles. ${ }^{14,15}$

\section{Macroflux $^{\circledR}$}

Macroflux $^{\circledR}$ technology is another novel transdermal drug delivery system that ALZA Corporation has developed to deliver biopharmaceutical drugs in a controlled reproducible manner that optimizes bioavailability and efficacy without significant discomfort for the patient. ${ }^{16}$

The system incorporates a titanium microprojection array that creates superficial pathway through the skin barrier layer to allow transportation of therapeutic proteins and vaccines or access to the interstitial fluids for sampling. Macroflux ${ }^{\circledR}$ has an area of up to $8 \mathrm{~cm}^{2}$ and contains as many as 300 microprojection per $\mathrm{cm}^{2}$ with individual micro projection length being $<200 \mu \mathrm{m}$. The maximal adhesive patch 
size is $10 \mathrm{~cm}^{2}$. A coating process is used to apply drug to the tip of each microprojection in the array. When the patch is applied to the skin, the drug-coated microprojections penetrate through the skin barrier layer into the epidermis. The microcapillaries for systemic distribution absorb the drug. The rate of absorption is promoted by the high local drug concentration around the microprojections and the large surface area provided by the patch array. ${ }^{17}$

Three types of Macroflux ${ }^{\circledR}$ have been designed and tested in preclinical studies. They include,

- Dry-Coated Macroflux ${ }^{\circledR}$ system for short duration administration that consist of a drug coated microprojection array adhered to a flexible polymeric adhesive backing.

- D-TRANS ${ }^{\circledR}$ Macroflux $^{\circledR}$ system for short duration administration that consist of a microprojection array coupled with a drug reservoir.

- E-TRANS ${ }^{\circledR}$ Macroflux ${ }^{\circledR}$ system for pulsatile or on demand delivery that include a microprojection array coupled with an electrotransport system. ${ }^{18}$

Therapeutic peptides, proteins and vaccines such as desmopressin, human growth hormone $(\mathrm{HGH}), \mathrm{TH} 9507$ (a human growth hormone releasing factor analog), ovalbumin(45000 Da protein) are in the developmental stage for transdermal delivery by Macroflux ${ }^{\circledR 19}$

\section{Metered-Dose Transdermal Spray (MDTS)}

Metered-dose transdermal spray (MDTS ${ }^{\mathrm{TM}}$ ), originally developed at the Victorian College of Pharmacy [Monash University (Parkville Campus), Parkville, Victoria, Australia] and currently being commercialized by Acrux Limited [Melbourne, Victoria, Australia] has the potential to expand the growth of TDD systems by broadening patient acceptance and pharmaceutical applications for enhanced TDD.

MDTS relies on the combination of a newly identified GRAS (generally recognized as safe) chemical penetration enhancer (Across ${ }^{\mathrm{TM}}$ ) and the accurate and precise topical dosing of a volatile: nonvolatile vehicle. This MDTS can be classified, as an enhanced, passive TDD system. ${ }^{18}$ It is a topical solution made up of a volatile cum nonvolatile vehicle containing the drug dissolved as a single-phase solution. A finite metered - dose application of the formulation to intact skin results in subsequent evaporation of the volatile component of the vehicle, leaving the remaining nonvolatile penetration enhancer and drug to rapidly partition into the stratum corneum during the first minute after application, resulting in a stratum corneum reservoir of drug and enhancer. ${ }^{20}$

Following a once daily application of the MDTS, a sustained and enhanced penetration of the drug across the skin can be achieved from the stratum corneum reservoir. Different types of penetration enhancers, such as ethanol and azone, are commonly used. ${ }^{21}$ Clinical experience with estradiol-MDTS to post-menopausal women have shown increased higher plasma level of estradiol than the baseline value measured by radioimmunoassay.

The MDTS has the following potential advantages:

1. Enhanced passive tdds with little or no skin irritation primarily as a result of its nonocclusive nature.

2. Improved cosmetic acceptability

3. Dose flexibility

4. Simplicity of manufacture. ${ }^{18}$

\section{Electrically-Based Enhancement Techniques}

Iontophoresis: Iontophoresis may be defined as the facilitation of ionizable drug permeation across the skin by an applied electrical potential, the driving force of which may be simply visualized as electrostatic repulsion. ${ }^{22}$ A typical iontophoresis device consists of a battery, microprocessor controller, drug reservoir and electrodes.

The technique involves the application of a small electric current (usually $0.5 \mathrm{~mA} / \mathrm{cm}^{2}$ ) to a drug reservoir on the skin, with the similarly charged electrodes (on the surface of the skin) placed together in the drug reservoir producing a repulsion effect that effectively drives the solute molecules away from the electrode and into the skin. $^{23}$

There are three explanations of how iontophoresis increases transdermal drug delivery. The first, proposes that the drugs are forced across the skin by simple electronic repulsion of similar charges. Anionic drugs can cross the skin by using a negatively charged 
electrode. Similarly cationic drugs enter the skin more successfully when a positively charged electrode is used The second, explanation suggests that the electric current enhances permeation by inhibiting the skin's ability to perform its protective barrier function. The third, states that iontophoresis causes water, a very effective penetration enhancer, to enter the stratum corneum by electro-osmosis. Dissolved drugs can be carried across the skin along with the penetrating water during iontophoresis. At physiological $\mathrm{pH}$, human skin has slight negative charge; therefore, certain cationic drugs can more easily cross the skin during iontophoresis due to reduced resistance. ${ }^{24}$

Several studies have addressed the application of iontophoresis to the delivery of low molecular weight solutes $(<500 \mathrm{Da})$. For delivery of macromolecules, proteins and peptides such as calcitonin, corticotrophin-releasing hormone, $\delta$ sleep- inducing peptide, dextrin sulphate, inulin, insulin, gonadotropin releasing hormone, growth hormone releasing factor, neutral thyrotrophinreleasing hormone, parathyroid hormone and vasopressin iontophoresis may also be utilized. To date, clinical studies have been limited to smaller molecules such as lidocaine, ketorolac dexamethasone, etofenamate, naproxen, vincristine, cortisone and fentanyl. ${ }^{25-27}$

\section{Ultrasound}

Ultrasound (sonophoresis, phonophoresis and ultraphonophoresis) is a technique for increasing the skin permeation of drugs using ultrasound (20 $\mathrm{KHZ}$ to $16 \mathrm{MHZ}$ ) as a physical force. It is a combination of ultrasound therapy with topical drug therapy to achieve therapeutic drug concentrations at selected sites in the skin. In this technique, the drug is mixed with a coupling agent usually a gel but sometimes a cream or ointment is used which transfers ultrasonic energy from the device to the skin through this coupling agent. $^{29}$

Application of low - frequency ultrasound (20 $100 \mathrm{KHZ}$ ) enhances skin permeability more effectively than high - frequency ultrasound (1 $16 \mathrm{MHZ}$ ). The mechanism of transdermal skin permeation involves disruption of the stratum corneum lipids, thus allowing the drug to pass through the skin. A corresponding reduction in skin resistance was observed due to cavitation, microstreaming and heat generation. ${ }^{30,}{ }^{31}$ Reverse ultrasound technology may also be used for the extraction of interstitial fluid samples for analysis. ${ }^{32}$

\section{Photomechanical Waves}

Photomechanical waves (PW's) are the pressure pulses produced by ablation of a material target (polystyrene) by Q-switched or mode-locked lasers. Photechanical waves are able to render the stratum corneum more permeable to macromolecules via a possible transient permeabilisation effect due to the formation of transient channels. The largest molecule that has been reported to be delivered through the rat skin to date has a molecular weight of $40,000 \mathrm{Da}$. Suggestions have been made that many clinically important proteins such as insulin (6000 Da) and hematoprotien (48000 Da) are within or close to the delivery capability range of PW's. However; this relatively new technique does not yet seem to have produced any human clinical data. ${ }^{33}$

\section{Electroporation}

This method involves the application of high voltage pulses to the skin, which has been suggested to induce formation of transient pores. High voltages in the form of direct current [DC (100 volts)] caused by electrical pulses with short treatment durations (milliseconds) are most frequently employed. Other parameters that affect delivery include pulse properties such as wave form, rate and number. The mechanism of penetration is the formation of transient pores due to electric pulses that subsequently allow the passage of macromolecules from the outside of the cell to the intracellular space via a combination of possible processes such as diffusion and local elctrophoresis. ${ }^{34-36}$

The electrical resistance of the skin is reported to drop as much as three orders of magnitude within microseconds of administration of an electric pulse. The technology has been successfully used to enhance the skin permeability of molecules with differing lipophilicity and size (i.e., small molecules, proteins, peptides and oligonucleotides) 
including biopharmaceuticals with molecular weights greater than $7 \mathrm{KDa}{ }^{37}$

Increase in transdermal penetration of up to $10^{4}$ fold have been reported in vitro for various sizes of molecules such as metoprolol, lidocaine, tetracaine, vitamin C, timolol and fentanyl dyes, including calcein and methylene blue, and macromolecules up to $40 \mathrm{KDa}$ including cyclosporineA, heparin, leutenising hormone releasing hormone, insulin, oligonucleotides and dextrans (MW $4.4-39 \mathrm{KDa})^{38-41}$

\section{Electro-Osmosis}

If a charged porous membrane is subjected to a voltage difference, a bulk fluid or volume flow, called electro osmosis occurs without concentration gradients, suggesting that this flow is not diffusion. This bulk fluid flow by electro osmosis was found to be of the order of micro liters per hour per square centimeter of hairless mouse skin. The electro - osmotic flow occurs from anode to cathode, thus enhancing the flux of positively charged (cationic) drugs and making it possible to deliver neutral drugs.

\section{Velocity Based Enhancement Techniques}

Needle-Free Injections

The highest value, least developed and most technically challenging group of needle-free technologies is prefilled, disposable injectors. The development of such technologies is primarily driven by the demand for a convenient,

Table 3: Comparison of methods of enhancing transdermal delivery

\begin{tabular}{lcccc}
\hline Delivery method & $\begin{array}{c}\text { Increased } \\
\text { transport }\end{array}$ & $\begin{array}{c}\text { Sustained } \\
\text { delivery }\end{array}$ & $\begin{array}{c}\text { No pain/ } \\
\text { irritation }\end{array}$ & $\begin{array}{c}\text { Low cost/ } \\
\text { complexity }\end{array}$ \\
\hline Chemical enhancers & +++ & ++ & + & +++ \\
lontophoresis & + & +++ & ++ & +++ \\
Electroporation & ++ & +++ & ++ & + \\
Ultrasound & ++ & +++ & +++ & + \\
Microneedles & ++ & +++ & +++ & + \\
Jet injection & +++ & + & + & + \\
Thermal Poration & ++ & +++ & +++ & +
\end{tabular}

$+=$ Limited, $++=$ Moderate and $+++=$ Good (This ranking is according to authors' opinions obtained through the literature review.)

Table 4: Marketed Products of Modified Transdermal Drug Delivery Technologies

\begin{tabular}{|c|c|c|c|}
\hline Enhancement Method & Brand Name & Company Name & $\begin{array}{l}\text { Drug product available/ } \\
\text { under consideration }\end{array}$ \\
\hline Microprojection & Macroflux & Alza Corporation & $\begin{array}{ll}\text { Vaccines, } & \text { Therapeutic } \\
\text { proteins } & \end{array}$ \\
\hline Iontophoresis & E-Trans & Alza Corporation & Fentanyl \\
\hline Ultrasound & SonoPrep ${ }^{\circledR}$ & $\begin{array}{l}\text { SontraMedical } \\
\text { Corporation }\end{array}$ & $\begin{array}{l}\text { Peptides, Other large } \\
\text { molecules }\end{array}$ \\
\hline Ultrasound & SonoDerm ${ }^{\mathrm{TM}}$ & Imarx & Large molecules (Insulin) \\
\hline Needleless injectors & Intraject & Weston Medical & Vaccines \\
\hline Needleless injectors & Powder Ject & $\begin{array}{l}\text { PowderJect } \\
\text { Pharmaceuticals Plc }\end{array}$ & Insulin \\
\hline Medicated Tattoos & Med-Tat & Lipper-Man Ltd. & Acetaminophen, Vitamin C \\
\hline Heat & CHADD & Zars, Inc & $\begin{array}{l}\text { S-Caine (lidocaine } \\
\text { tetracaine) }\end{array}$ \\
\hline Laser Radiation & $\begin{array}{l}\text { Transdermal } \\
\text { assisted delivery }\end{array}$ & Norwood Abbey & Wide range of drugs \\
\hline
\end{tabular}


non-invasive alternative to the conventional needle and syringe injection. The earliest needle free injectors became available as early as 1866, when the French company H.Galante manufactured an "Apparatus for aqua puncture". ${ }^{18}$ Some of the needle free injectors under development are:

(a)-Intraject ${ }^{\circledR}$ : One of the prefilled disposable injectors, intraject, under development, is designed to use the nitrogen propelled device which has a blank drug capsule. The patient snaps off the tip, tears off the safety end and plenus the nozzle against the skin pressurized gas, and then pushes the liquid formulation through a narrow orifice into the skin.

(b)-Implaject ${ }^{\circledR}$ : Implaject first pushes a tiny, potential "Pioneer tip" thorough the skin ahead of the drug. The tip pierces the tissue, creating a channel through which the therapeutic agent follows immediately.

(c)-Jet Syringe ${ }^{\circledR}$ : The jet syringe, which can deliver up to $0.5 \mathrm{ml}$; can be configured with an adjustable dose fillable ampoule or proprietary prefilled glass ampoule for fixed dose applications. It is suitable for short-term infrequent injection therapies.

(d)-lject ${ }^{\circledR}$ : The design of lject is based on Biojector 2000. It is a light weight, hand-held liquid NFI [Needle-free injectors]. It can deliver 0.1 to $1.0 \mathrm{ml}$ subcutaneously and intramuscularly.

(e)-Mini-ject ${ }^{\circledR}$ : The Mini-ject system utilizes a glass drug cartridge to accommodate for longterm drug storage and stability; a polycarbonate syringe, to accommodate for a wide range of pressure profiles; and a proprietary multiphase energy system that can deliver a specific pressure profile to ensure that the entire drug is delivered comfortably. It can target specific tissue layers including the dermal, subcutaneous and intramuscular layers.

(f)-Crossjet ${ }^{\circledR}$ : It comprises three modules. The gas generator contains the chemical energy source and is triggered by the impact of a syringe, the drug container and the third module, nozzle, of polycarbonate with one or more orifices depending on the quantity of the formulation.

The outer layers of the skin using a suitable energy source, usually a compact gas source, is used to propel a pre-measured quantity of liquid medicine through the skin and into the underlying subcutaneous tissue, without the use of a needle. The needle-free devices have been developed for the delivery of drugs such as insulin, sumatriptan and human growth hormone. . $^{4,44}$

\section{Powderject Device}

The core technology involves the high velocity injection of particle formulated drugs and vaccines into any physically accessible tissue. These may be for therapy or prevention of disease and may be small molecules, peptides, proteins and genes. The Powderject system involves the propulsion of solid drug particles into the skin by means of high-speed gas flow. This needle-free method is painless and causes no bleeding and damage to the skin. ${ }^{31}$ The use of compressed gas to force solid drug particle through a convergent divergent nozzle was reported by Bellhouse et al. ${ }^{45}$ using compressed helium. Drug particle velocities of up to $800 \mathrm{~m} / \mathrm{s}$ were obtained at the nozzle exit. Adjusting the momentum density of the particles within the gas flow optimizes the depth of penetration of the drug particles. Particle velocity is controlled within the device by three parameters namely nozzle geometry, membrane burst strength and gas pressure. ${ }^{45}$ Powderject system consists of a gas canister that allows helium gas at high pressure to enter a chamber at the end of which drug cassette containing powdered drug between two polycarbonate membranes. At the release, virtually instantaneous rupture of both membranes causes the gas to expand rapidly, forming a strong shock wave that travels down the nozzle at speed of $600-900 \mathrm{~m} / \mathrm{s}$. Powderject device has been reported to successfully deliver testosterone, lidocaine hydrochloride, and macromolecules such as calcitonin and insulin. ${ }^{18}$ 33

\section{Other Enhancement Techniques}

Transfersomes

To date, the most promising transdermal drug carrier is the recently developed and patented Transfersome ${ }^{\circledR}$ which penetrates the skin barrier along the transcutaneous moisture gradient. ${ }^{18}$ This leads the carriers through the "virtual " 
pores between the cells in the organ without affecting its biological and general barrier properties. Lipid - based suspensions, such as liposomes and niosomes, have been proposed as low-risk drug carriers. Transfersome carriers can create a highly concentrated drug depot in the systemic circulation. $^{18}$ Liposomes are microscopic bilayer vesicles, which are usually made of phospholipids (mainly phosphatidylcholine) and cholesterol, contain both hydrophilic and lipophilic portions and can serve as carriers for polar and non polar drugs. Niosomes have a similar morphology, but are made of nonionic surfactants, typically alkyl polyoxyethylene ethers, mixed with cholestrol. ${ }^{30}$ Transfersomes contain at least one component that controllably destabilizes the lipid bilayers and thus makes the vesicles very deformable. Additives useful for this purpose are bile salts, polysorbates, glycolipids, alkyl or acyl - poly ethoxylenes etc. Transfersome carriers loaded with various agents of different molecular size and lipophilicity (lidocaine, tetracaine, cyclosporine, diclofenac, tamoxifen, etc.) have been shown to cross the skin barrier. In addition, polypeptides such as calcitonin, insulin, $\alpha$ - and $\gamma$ - interferon, and, $\mathrm{Cu}-\mathrm{Zn}$ super oxide dismutase, serum albumin, and dextrose have been successfully delivered across the skin with transfersome carriers. ${ }^{18,46}$

\section{Medicated Tattoos}

Med-Tats is a novel means of delivering compounds transdermally and is produced by Lipper-Man Ltd [Morristown, N.J.]. Medicated Tattoo (Med-Tat) is a modification of temporary tattoo which contains an active drug substance for trandermal delivery. Med-Tats are applied to clean, dry skin in the same manner as traditional temporary tattoos and, according to Lipper Man Ltd, are not unsightly but rather are attractive and fun to wear. There is no predetermined duration of therapy for Med-Tats; instead, the manufacturer provides a color chart that can be compared to the color of the patient's tattoo to determine when the tattoo should be removed. This visual comparison, which relies on the dyes incorporated into the patch, introduces a significant amount of interpatient variability. Drugs and other compounds used in Med-Tats prototypes include acetaminophen and vitamin C. The main advantage of medicated tattoos is the delivery of drugs to children who cannot tolerate more traditional dosage forms. ${ }^{47}$

\section{Skin Abrasion}

The abrasion technique involves the direct removal or disruption of the upper layers of the skin to facilitate the permeation of topically applied medicaments. Some of these devices are based on techniques employed by dermatologists for superficial skin resurfacing (e.g., microdermabrasion) which are used in the treatment of acne, scars, hyperpigmentation and other skin blemishes. Microscissuining is a process which creates microchannels in the skin by eroding the impermeable outer layers with sharp microscopic metal granules. Carlisle Scientific [Carlisle, MA] is currently in the process of developing a pen - like handheld device called the microscissioner. In addition, Med Pharm Ltd. [Charlbury, United Kingdom] had recently developed a novel dermal abrasion device (D3S) for the delivery of difficult to formulate therapeutics ranging from hydrophilic low molecular weight compounds to biopharmaceuticals. In vitro data have shown that the application of the device can increase the penetration of angiotensin into the skin 100fold compared to untreated human skin. ${ }^{48,49}$

\section{Controlled Heat Aided Drug Delivery (CHADD) System}

Heat increases skin temperature that leads to increase in microcirculation and blood vessel permeability, thus facilitating drug transfer to the systemic circulation.

Drug solubility, both in the patch formulation and within the skin increase with a rise in temperature. Zars, Inc [Salt Lake City, UT, USA] has developed a technology that takes advantage of heat's ability to increase transdermal permeation. This technology is known as Controlled Heat-aided Drug Delivery (CHADD) system. CHADD system is a small heating unit that can be placed on top of a traditional patch. An oxidation reaction within the unit provides heat at a limited intensity and duration. 
The disadvantage of this technology is that heat can slightly compromise the barrier function of the skin. ${ }^{50,51}$

\section{Laser Radiation}

This method involves direct and controlled exposure of a laser beam to the skin which results in the ablation of the stratum corneum without significantly damaging the underlying epidermis. Removal of the stratum corneum using this method has been shown to enhance the delivery of lipophilic and hydrophilic drugs. ${ }^{52}$ In 1991, Nelson et al. reported that mid-infrared laser $\left(1 \mathrm{~J} / \mathrm{cm}^{2}\right)$ ablation of pig stratum corneum enhanced the permeation of both hydrocortisome and interferon. ${ }^{53}$

A handheld portable laser device has been developed by Norwood Abbey Ltd. (Victoria, Australia) that has been approved by the U.S. and Australian regulatory bodies for the administration of a topically applied anaesthetic. However, the structural changes caused by this technique still need to be assessed for safety and reversibility, particularly at the higher intensities that may be needed to enhance the penetration of large molecular weight solutes where evidence of deeper level ablation effects exist. $^{54,55}$

\section{Magnetophoresis}

Magnetophoresis is a novel approach in enhancing drug delivery across biological barriers. Benzoic acid, a diamagnetic substance, was selected as a drug candidate. The influence of magnetic field strength on diffusion flux was determined and was found to increase with increasing applied strength. ${ }^{56}$

\section{CONCLUSION}

Transdermal drug delivery is hardly an old technology, and the technology is no longer just adhesive patches. Due to recent advances in technology and the ability to apply the drug to the site of action without rupturing the skin membrane, transdermal route is becoming a widely accepted route of drug administration. However, the development of DDS is also getting increasingly expensive. The newer API's are far more active and hence they need to be delivered in a controlled manner. The use of the transdermal route has been well established since the 1800s. In addition to currently marketed formulations, new drugs are being formulated as transdermal systems because of the inherent advantages of administration of this route. Modification of transdermal drug delivery systems can enhance the bioavailability of poorly absorbed drugs that leads to rapid increase in market value. Transdermal drug delivery technologies are becoming one of the fastest growing sectors within the pharmaceutical industry. Advances in drug delivery systems have increasingly brought about rate-controlled delivery with fewer side effects as well as increased efficacy and constant delivery. The future of transdermal rate controlled drug delivery is expected to grow phenomenonally, and biomedical application of TDDS is expected to increase with the successful development of new approaches capable of enhancing the skin permeability of drugs.

\section{REFERENCES}

1. Langer R. Transdermal drug delivery: past progress, current status, and future prospects. Advanced Drug Delivery Reviews 2004; 56: 557-58.

2. Prausnitz MR, Mitragotri S, Langer R. Current status and future potential of transdermal drug delivery. Nature Reviews 2004; 3: 115-24.

3. Jain N, Talegonkar S, Jain N K. New ways to enter the blood stream: Emerging strategies in transdermal drug delivery. The Pharma Review 2004; Oct.: 4159.

4. Barry B. Transdermal drug delivery. In: Aulton, E M.(ed). Pharmaceutics, The science of dosage forms design, ed 2, Churchill Livingstone, Newyork, Harcourt publishers, 2002: 499-33.

5. Kumar P, Sankar C, and Mishra B. Delivery of macromolecules through skin. Pharmacist 2004; 7-17.

6. Ansel H C, Loyd A V, Popovich N G, Pharmaceutical dosage system, ed 7, Lippincott Williams and Willkins publication

7. Finnin C B. Transdermal drug delivery-What to expect in the near future. Business briefing: Pharma tech. 2003; 192-93.

8. Chien $\mathrm{Y}$ W. Transdermal drug delivery and delivery system. Marcel Dekker, Inc. New York, 1992; 50: 301-381.

9. Barry B W. Novel mechanisms and devices to enable successful transdermal drug delivery. Eur. J. Pharm. Sci 2001; 14: 101-14.

10. Gordon RD, Peterson TA. Four myths about transdermal drug delivery. Drug Delivery Technology 3(4): (http://www.drugdeliverytech.com/cgibin/articles.cgi?idArticle=143), June 2003. 


\section{Philip \& Kumar}

11. Jones S A. Evolution of transdermal drug delivery: Recen29. Mormito $Y$, Mutoh M, Ueda H, Fang L, Hirayama K, progress in active drug delivery technologies has helped miniature, powerful device to generate required clinical responses.www.pharmaquality.com.

12. Gerstel M S and Place V A. Drug delivery device.1976; Patent (Serial No. US, 3,964,482).

13. Trautman J, Wong P S, Daddona P E, Kim H L, and Zuck M G. Device for enhancing transdermal agent flux. 2001; Patent (Serial No.US, 6,322,808 B1).

14. ALZA website, http://www.alza.com/, Retrieved.

Atobe M, Kobayashi D. Elucidation of the transport pathway in hairless rat skin enhanced by lowfrequency sonophoresis based on the solute water transport relationship and confocal microscopy. J. Control Release 2005; 103: 587-597.

30. Mitragotri S, Kost J. Transdermal delivery of heparin and low-molecular weight heparin using low-frequency ultrasound. Pharmaceutical Research 2001; 18: 1151-56.

15. McAllister DV, Wang PM, Davis SP, Park JH, Canatella PJ31. Tang H, Wang C C J, Blankschtein D, Langer R. An Allen MG, Prausnitz MR. Microfabricated needles for transdermal delivery of macromolecules and nanoparticles: fabrication methods and transport studies. Proceedings of the National Academy of investigation of the role of cavitation in lowfrequence ultrasound-mediated transdermal drug transport. Pharmaceutical Research 2002; 19: 1160-69.

Sciences of the United States of America 2003;10032. Terahara T, Mitragotri S, Langer R. Porous resins as a 13755-60.

16. Daddona P. Macroflux ${ }^{\circledR}$ transdermal technology development cavitation enhancer for low-frequencey sonophoresis. J. Pharm. Sci. 2002; 91: 753-59. for the delivery of therapeutic peptides \& proteins33. Cross S E, and Roberts M S, Physical enhancement of Drug Deliv. Tech. 2002; 2(5): 54-57.

17. Lin W, Cormier M, Samiee A. Transdermal delivery of antisense oligonucleotides with microprojection patch (Macroflux $^{\circledR}$ ) technology. Pharm Res. 2001; 18: 178993.

18. Rathbone M J, Hadgraft J, Roberts M S (eds.) Modifiedrelease drug delivery technology. New York, Marcel Dekker, Inc., 2004; vol.126: 471-619.

transdermal drug application: Is delivery technology keeping up with pharmaceutical development. Current drug delivery 2004; 1: 8192.

34. Prausnitz M R. A practical assessment of transdermal drug delivery by skin electrporation, Adv. Drug Deliv Rev. 1999; 35: 61-76.

35. Benga A K, Bose S and Ghosh T, K, lontophoresis and electroporation: comparisions and contrasts. Int J. Pharm., 179: 1-19.

19. Morgan T M, Read B L, Finnin B C, Enhanced skin permeation of sex hormones with novel topical spray vehicles, J. Pharm. Sci.1998; 87: 1213-18.

36. Zhang L, Li L, Hoffmann GA, Hoffman RM. Depthtargeted efficient gene delivery and expression in the skin by pulsed electric fields: an approach to gene therapy of skin aging and other diseases. Biochem. and Biophy. Res. Comm. 1996; 220: 633-36.

21. Finnin B C, Morgan T M. Transdermal penetration enhancers: applications, limitations, and potential. J. Pharm. Sci. 1999; 88: 955-58.

22. Vyas S P, and Khar R K. Contolled drug delivery-Concepts and advances, ed 1 ,Vallabh prakashan Delhi, India, 2005; 411-25.

23. Roberts M S, Lai P M, Cross S E, Yoshida N H. Mechanism oß8. Wallace MS, Ridgeway B, Jun E, Schulteis G, Rabussay transdermal drug delivery. Marcel Dekker, Newyork, 1997, 291-49.

24. Guy R H, Kalia Y N, Delgado-Charro M B. Iontophoresis: electrorepulsion and electroosmosis. J. Control Release 2000; 64: 129-32.

25. Alza corporation, E-TRANS technology: how does it work? Available at www.alza.com/wt/how.zoo? page_name=etrans_h ow.

26. Tiwari S B, Udupa N, Investigation into the potential of iontophoresis facilitated delivery of ketorolac. Int. J. Pharm. 2003; 260: 93-103.

27. Gattani S G, Gaud R S, Chaturvedi S C, Surana S J, Nandve M D. Iontophoresis: "Noninvasive" Electrically controlled technologies. The Pharma Review 2005; 113-18.

28. Vedah $H$, Oginara $M$, Sugibayasnik K, Morimoto $Y$. Change in the electrochemical properties of skin and the lipid packing in stratum corneum by ultrasonic irradiation. Int. J. Pharm. 1996; 137: 217-24.
37. Hofmann GA. Instrumentation and electrodes for in vivo electroporation. In: Methods in Molecular Medicine. Press, Totowa, NJ. 2000; 37-61.

$D$, Zhang L. Topical delivery of lidocaine in healthy volunteers by electroporation, electroincorporation, or iontophoresis: an evaluation of skin anesthesia. Regional Anesthesia and Pain Medicine 2001; 26: 229-38.

39. Zhang L, Lerner S, Rustrum WV, Hofmann GA. Electroporation-mediated topical delivery of vitamin C for cosmetic applications. Bioelectrochemistry and Bioenergetics 1999; 48: 453-61

40. Prausnitz MR, Edelman ER, Gimm JA, Langer R, Weaver JC. Transdermal delivery of heparin by skin electroporation. Biotechnology 1995; 13: 1205-09.

41. Sen A, Daly M E, Hui S W. Transdermal insulin delivery using lipid enhanced electroporation. Biochimica et Biophysica Acta. 2002; 1564 (1): 5-8.

42. Abla N, Naik A, Guy R H, and Kalia Y N. Contributions of electromigration and electroosmosis to peptide, iontophoresis across intact and impared skin. J. Contr. Rel. 2005; 108: 319-330.

43. Berg J. New development improve transdermal delivery of drugs, BBI Newsletters, available at:www.find articles.com. Jaroszeski MJ, Heller R, Gilbert R. Eds. Humana 


\section{Philip \& Kumar}

44. Furness G. The two faces of the needle-free injection technology. Drug Del.Tech. 2004; 4(6): 38-43.

45. Bellhouse B J, Sarphie D F and Greenford J C. U.S. Pats. 5, 630, 796, 5, 899, 880 and EP 0693119; 1994-99.

46. Cevc, G. "Transfersomes, liposomes and other lipid suspensions on the skin: penetration enhancement, vesicle penetration and transdermal drug delivery" Crit. Rev. Ther. Drug Carrier Syst. 1996; 13: 257-388.

47. Lipper-Man Ltd., Competitive advantages, www.lipperman.com/competitive.htm.

48. Roberts MS, Targeted drug delivery to the skin and deeper tissues: role of physiology, solute structure and disease. Clin Exp Pharmacol Physiol. 1997 Nov; 24(11): 874-9.

49. Murthy SN, Sen A, Zhao YL, Hui SW. pH influences the postpulse permeability state of skin after electroporation. Journal of Controlled Release 2003; 93: 49-57.

50. Murthy SN, Sen A, Zhao YL, Hui SW. Temperature influences the postelectroporation permeability state of the skin. Journal of Pharmaceutical Sciences 2004; 93: 908-15.
51. Zars, Inc. Zars drug delivery technology. Available at: http://www. Zars.com/chadd.html

52. Lee W R, Shen S C, Wang K H, Hu C H, Fang J Y. The effect of Laser treatment on skin to enhance and control transdermal delivery of 5-flurouracil. J. Pharm. Sci. 2002; 91 (7): 1613-26.

53. Nelson J S, McCullough J L, Glenn T C, Wright W H Liaw $L$ H, Jacques $S \mathrm{~L}$. Mid-infrared laser ablation of stratum corneum enhances in vitro percutaneous transport of drugs. J. Invest. Derm. 1991; 97(5): 874-79.

54. Wang $\mathrm{K} \mathrm{H}$, Fang J Y, Hu C H, Lee W R. Erbium: YAG Laser pretreatment accelerates the response of Bowen's disease treated by topical 5-flurouracil. Dermatol. Surg. 2004; 30(3): 441-5

55. Lee W R, Shen S C, Kuo-Hsien W, Hu C H, Fang J Y. Laser and microdermabrasion

enhance and control topical delivery of vitamin C. J. Invest Dermatol. 2003; 121(5): 118-25.

56. Murthy S N. Magnetophoresis: an approach to enhance transdermal drug diffusion. Pharmazie 1999; 54(5): $377-9$. 